\title{
The Life Assessment of API 5L Grade B Geothermal Pipeline in Correlation with Corrosion under Insulation
}

\author{
Handoko Subawi ${ }^{1}$ and Budi Lukman Hakim ${ }^{2}$ \\ 1. Directorate of Production, Indonesian Aerospace, Bandung 40174, Indonesia \\ 2. Directorate of Operation, Global Engineering Solutions, Bandung 44151, Indonesia
}

Received: August 18, 2014 / Accepted: September 30, 2014 / Published: December 31, 2014.

\begin{abstract}
The corrosion under insulation dominates metal loss in the case of API (American Petroleum Institute) 5L Grade B geothermal pipeline, whereas, the other possible corrosion causes, such as stress corrosion and thermal cracking, did not serve a role as critical factors regarding to pipeline degradation during 26-years working operation. Actually, the header pipe diameter 32 inches and 40 inches require priority for inspection due to higher corrosion rate compared to smaller pipe diameters. By simulation method on similar heavy duty service condition in which the working pressure of 15 bars and temperature of $183{ }^{\circ} \mathrm{C}$, it was proved that corrosion rate will severely occur at corrosion rate more than 10 mpy in the pipe diameters of 20 inches, 32 inches and 40 inches. Further, condensation factor may contribute more significant in the case of corrosion under insulation. Practically, the metal loss at a half initial thickness requires priority for inspection, intensive maintenance or possible partial replacement.
\end{abstract}

Key words: Corrosion under insulation, corrosion rate, geothermal, pipe life, condensation index.

\section{Introduction}

Recently, the pipeline degradation due to CUI (corrosion under insulation) in power generating facilities, and other plants have started getting close attention worldwide. The pipe insulation that had been used in locations at $150{ }^{\circ} \mathrm{C}$ or higher, being used in temperature ranges lower than $100{ }^{\circ} \mathrm{C}$. The non-destructive inspection techniques, such as ultrasonic, radiography and eddy current, have been developed and applied at working sites, but they are not complete yet. Therefore, visual inspection and the ultrasound testing where the insulation is peeled off of the entire length of all surfaces are recommended to monitor the steam pipeline condition and to ensure the safety of transportation through piping system [1].

The external insulation coverings on pipelines and vessels may lead to severely corrosion than would be expected if they were uncoated. The main sources of

Corresponding author: Handoko Subawi, resource person, research field: production engineering. E-mail: handoko_subawi@yahoo.com. water under insulation are from condensation and external sources, such as rain, cooling tower discharge, condensate dripping from cold equipment above, steam discharge, process liquid spillage. Ingress of water can be prevented by adequate weatherproofing of the insulation materials. However, it is not possible to completely prevent the penetration of water vapor from the atmosphere, and therefore, condensation can form on the metal surface underneath the insulation [2].

Since the majority of construction materials used in plants is susceptible to corrosion under insulation degradation, corrosion mitigation is best achieved by using appropriate paints/coatings and maintaining the insulation barriers to prevent moisture ingress. Corrosion under insulation occurs when water enters external insulation through holes or cleavages in the insulation covering, or when moisture in the air condenses on the metal surface below the insulation. Entrapped water tends to collect at low spots at the watch arrow direction of 5 to 7, insulation support rings and other external appendages. If an adequate 
protective coating is not present, significant external corrosion can occur. CUI attack is difficult to detect due to hidden under the insulation [3].

The critical factors in a pipeline design may consider insulation system, insulation type, temperature service, internal pressure and environment condition. Corrosion rates may increase significantly with increasing metal temperature up to the point where the water evaporates quickly. Corrosion becomes more severe at metal temperatures over the boiling point $100{ }^{\circ} \mathrm{C}$ up to $120{ }^{\circ} \mathrm{C}$, where water is less likely to vaporize and insulation stays wet longer. The corrosion of sulfur contained steam may occur through the reaction between sulfur and iron that produces a layer of iron sulfide scale on the inside surface of piping. This reaction can be compared to the occurrence of oxygen which may react with iron and produce rust.

The type of scale formed by sulfide corrosion is dependent upon the components contained in the steel. Sulfide corrosion affecting steel alloys that contains greater than $2 \%$ by weight chromium produces a protective scale that inhibits the further reaction between the iron and sulfur compounds, thereby reducing corrosion rates. With increasing percentages of chromium, the reaction is further slowed, greatly diminishing corrosion rates. For example, stainless steel containing $18 \%$ by weight chromium alloys is nearly 15 times more resistant to sulfide corrosion than stainless steel with $9 \%$ by weight chromium alloy.

The sulfide corrosion rates are significantly higher in steels containing very little chromium. Carbon steel material was manufactured with a maximum concentration of $0.40 \%$ chromium. The formed scale on carbon steel is less protective and allows continued reaction between the sulfur compounds and iron. Therefore, carbon steel corrodes at a rate that is significantly faster than other materials of construction, such as high chromium steels $[4,5]$.

The carbon steel also experiences significant variation in corrosion rates due to variances in silicon content used in the steel manufacturing process.
Carbon steel piping containing silicon content less than $0.10 \%$ by weight can corrode at accelerated rates, up to 16 times faster than carbon steel piping containing higher percentages of silicon. Corrosion rate of carbon steel containing 0.15 to 0.3 weight percentage silicon may reach up to $1 \mathrm{mpy}$, however, carbon steel with silicon content less than $0.075 \%$ may cause corrosion rate up to 16 mpy.

The corroded location forms a tubercle which is covered by a magnetic black inner crust consisting of hydrous, $\mathrm{Fe}_{3} \mathrm{O}_{4}$, which is devoid of oxygen. The outer crust consists of reddish brown ferric hydroxide or hydrated ferric oxide, $\mathrm{Fe}_{2} \mathrm{O}_{3}$. In ferrous metals, pits generally become inactive after a period of time. When this occurs, they no longer protect the metal in their vicinity, and further develop new pits. Apparently, the tubercles become so impermeable that ions cannot diffuse through, and since the solution inside must maintain electrical neutrality, no additional iron ions are formed [6].

The measurement of the corrosion rates of a carbon steel exposed to different concentrations, in ppm, of $\mathrm{O}_{2}$, $\mathrm{CO}_{2}$ and $\mathrm{H}_{2} \mathrm{~S}$ gasses dissolved in water, show that $\mathrm{O}_{2}$ is about 80 times more corrosive than $\mathrm{CO}_{2}$ and 400 times more corrosive than $\mathrm{H}_{2} \mathrm{~S}$. Whereas, corrosive effects of $\mathrm{NaCl}$ (sodium chloride) can be measured as the weight percentage of $\mathrm{NaCl}$ increases up to about $5 \%$, and the corrosion rate increases rapidly. Increasing the salt content above this reduces the solubility of oxygen, so the corrosion rate decreases at about $15 \% \mathrm{NaCl}$, and the rate is less than that with fresh water [7].

The corrosion grading system used by APSC (Alyeska Pipeline Service Company) is consistent with NACE (National Association of Corrosion Engineers) RP0775-91. The average of corrosion rates are classified as sufficiently low if less than 1 mpy, moderate rate from 1 to $4.9 \mathrm{mpy}$, high rate from 5 to 10.0 mpy and severe rate more than 10.0 mpy. Based on this grading system, a target rate of 1.0 mpy general corrosion rate or 5 mpy pitting rate implies that the corrosion is under control [8]. 


\section{Experimental Method}

This study evaluated corrosion under insulation data were gathered from geothermal power generation field includes PL-401, PL-402, PL-403, and PL-404. A visual inspection was started by identifying areas where damage and breaks to the weatherproofing potentially allowing water ingress are visible. If no areas of damaged weatherproofing are visible, then, inspections concentrate on the surfaces exposed to frequent hot to cold cycles, horizontal pipe work, especially, where there are joints and branches extending from the base.

The preliminary inspection is performed by opening small sections of the insulation at regular intervals across the pipework to allow inspection of the condition of the metal surface below. Real time radiography using Iridium-192 radiation source on medical film was used to investigate any possible crack due to stress corrosion cracking. Metallographic analysis was also performed to investigate any possible thermal cracking on a microstructure scale.

The measurement points were preferably selected on well head to header. At each pipe location was measured four times as 12, 3, 6 and 9 watch positions. The wall thicknesses were measured three times on each position. The value of wall thicknesses were selected as minimum thickness during measurement using General Electric DMS (Database Management System) 2 ultrasonic thickness gauge equipped with General Electric HT-400 (high temperature) probe, HPM (High Pressure Microscope) densitometer system and 2 GM (General Motors) sensing couplant.

An ultrasonic wall thickness measurement was used to inspect for both internal corrosion and corrosion under insulation. A small portion of the insulation needs to be removed to attach the probe ring to the structure. The ring transmits ultrasonic waves through the structure. The echo of these waves is then used to assess the wall thickness. The waves are able to travel across straight sections, bends supports, welds and even buried or otherwise inaccessible sections. The calculation method of corrosion rate and remaining life of assets referred to API 510 of Pressure Vessel Inspection Code [9].

\section{Result and Discussion}

\subsection{Fluid Flow}

The design and operating parameters of fluid flow in geothermal steam pipeline include PL-401 to PL-404 areas to power plant laid out. The applied pipe material was API 5LGrade B per ASME (American Society of Mechanical Engineers) B31.3 code with specified minimum yield strength of 35,000 psi. The maximum allowable stress refers to design depending on material type and operating temperature. The value of maximum allowable stress was between $40 \%$ and $75 \%$ of specified minimum yield strength. The pipe material of API 5L Grade B uses allowable stress value of 15,000 psi.

The steam flow in geothermal pipeline contained relatively low chloride contaminant. The steam fluid flows at sufficiently high temperature up to $200^{\circ} \mathrm{C}$. As the composition ratio of carbon dioxide-to-hydrogen sulfide was 60 , this means that the contribution of corrosion rate was higher than that of sulfide gas due to $\mathrm{CO}_{2}$. However, free oxygen and moisture outside the pipeline serves a role as the most significant cause of corrosion under insulation in this pipeline area.

\subsection{Metal Loss}

Ultrasonic testing measured metal loss on geothermal pipeline. The pipeline employs low carbon steel API 5L Grade B. The steam sources on PL-401 to PL-404 supply dry steam to generate electrical power in West Java Province. Pipeline has operated during 26 years since construction in 1983 and started to operate in 1987. Fig. 1 shows chart of CUI corrosion rate on various pipe diameters at operating temperature of 183 ${ }^{\circ} \mathrm{C}$ and actual different pressures either 6.5 bars (pipes diameters of 10 inches and 20 inches), 15 bars (pipe diameter 32 inches), or 10.3 bars (pipe diameter 40 inches). 

with Corrosion under Insulation

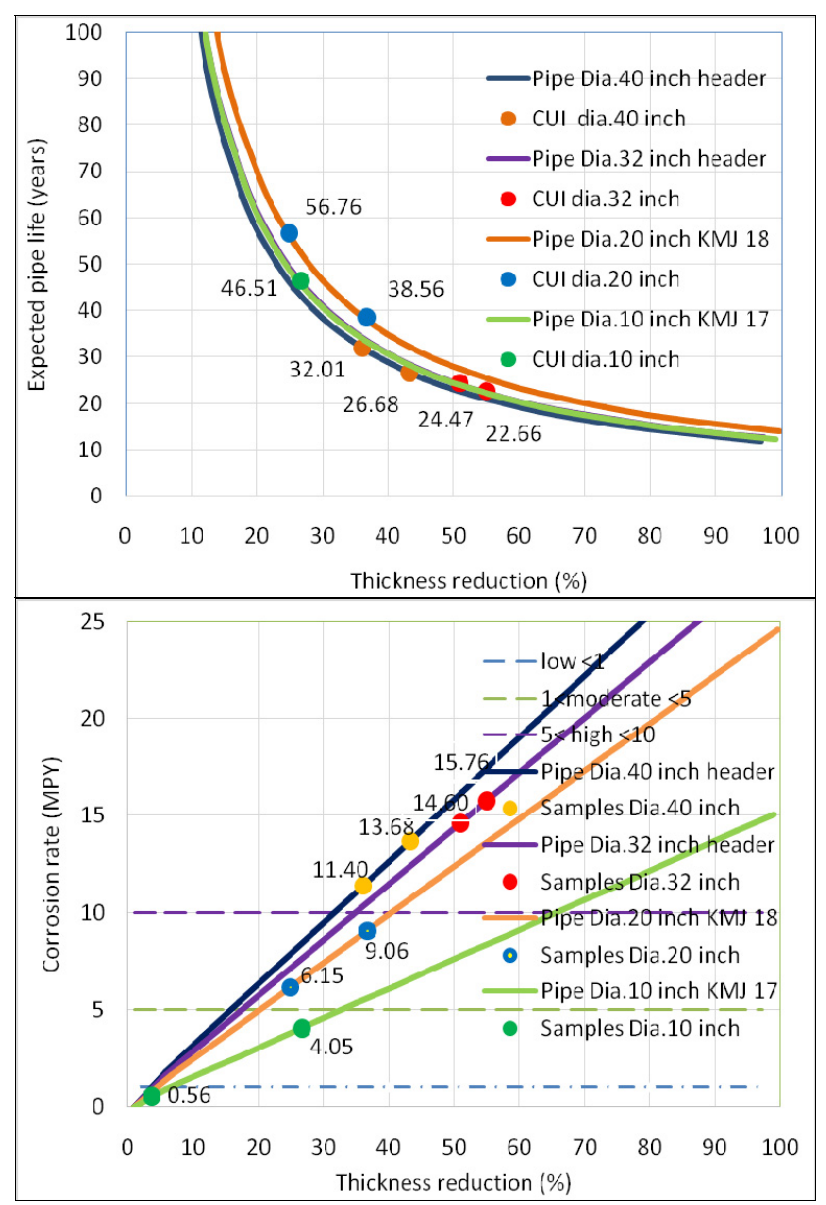

Fig. 1 Corrosion rate and pipe life at actual condition.

It shows that higher corrosion rate under insulation occurs on higher pipe diameter. However, pipe diameter 20 inches shows tendency of longer remaining pipe life than other pipe diameter. The CUI on pipe diameter 10 inches shows lower corrosion rate than larger diameter in the range of low to moderate corrosion rates, while pipe diameter of 20 inches shows high corrosion rate. Whereas, pipe diameters of 32 inches and 40 inches show severely corrosion rate more than 10 mpy.

In fact, the steam flows in pipe diameter 40 inches at low pressure of 6.5 bars, causes severe corrosion rate. This corrosion rate may sharply increase, if the steam flow will be operated at higher pressure up to 15 bars. Therefore, it will be more reasonable to compare the corrosion rate characteristic in typical operating condition on maximum allowable pressure. This simulation intends to predict an increase of corrosion rate or a decrease of pipe life expectation, while pipe, elbow and other fittings will be operated on maximum allowable pressure.

\subsection{Corrosion Severity}

The calculation method was prepared to evaluate the corrosion rate in heavy duty condition of operating pressure at the temperature of $185 \pm 3{ }^{\circ} \mathrm{C}$. The actual operating pressure of 15 bars applied in pipe diameter 32 inches was selected as base reference. The calculation result is represented in Fig. 2, which covers steam flow in various pipe diameters of 10 inches, 20 inches, 32 inches and 40 inches. The chart shows correlation between corrosion rate and expected pipe life for each pipe diameters.

The pipe diameter 20 inches shows the preference situation while compared with smaller and larger diameter at operating condition of temperature $183{ }^{\circ} \mathrm{C}$ and simulated operating pressure of 15 bars. Elbows
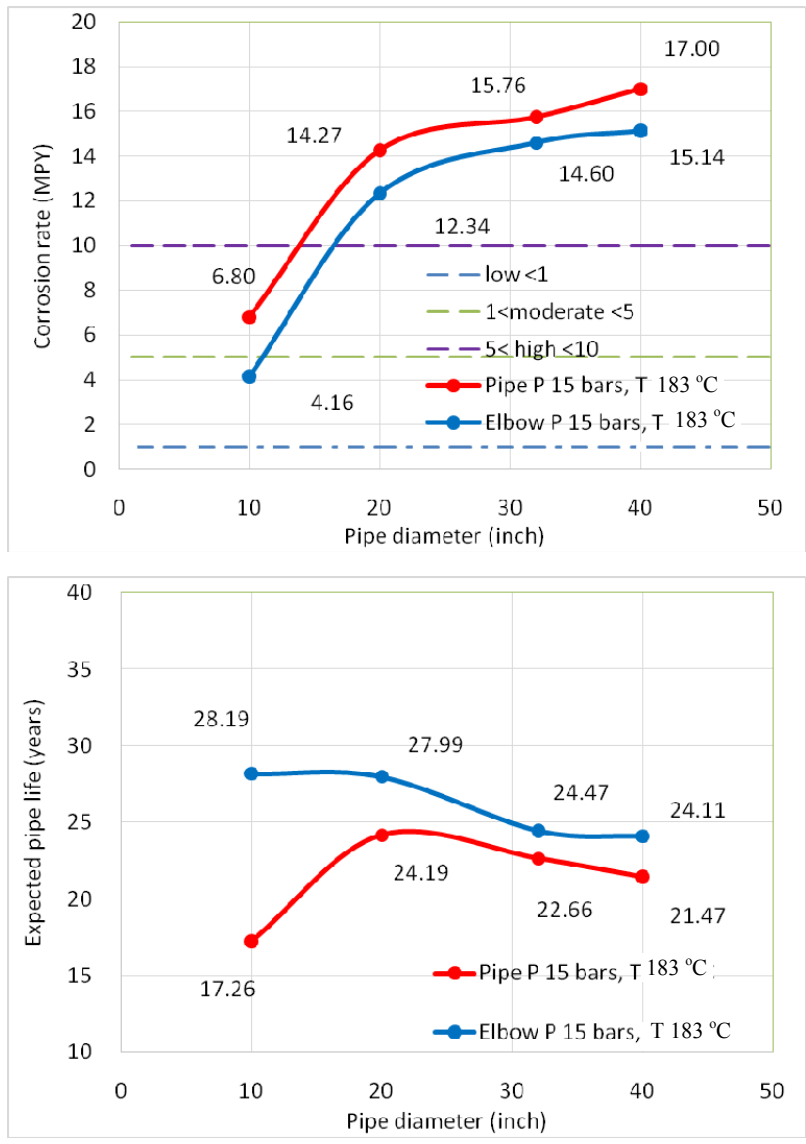

Fig. 2 Corrosion rate and pipe life at $183^{\circ} \mathrm{C}$ and 15 bars. 
show lower corrosion rate than pipe or header with similar diameter. Elbow with diameter up to 20 inches tends to have typical pipe life at about 28 years, but the elbow with larger diameter than 20 inches tends to show shorter pipe life expectation.

While operated in heavy duty operating condition, it was found that smaller diameter pipe has shorter pipe life and tends to increase sharply up to diameter 20 inches with expected pipe life may reach 24 years at working temperature of $183{ }^{\circ} \mathrm{C}$ and operating pressure of 15 bars. With similar operating condition, the larger pipe diameters of 32 inches and 40 inches have shorter pipe life at about 21 to 22 years, respectively, due to heavy duty application.

It can be said that applying the lower operating pressure will significantly reduce corrosion rate and prolong pipe life expectation. Conversely, by applying heavy duty condition at temperature $183{ }^{\circ} \mathrm{C}$ and high operating pressure up to 15 bars, the corrosion rate may reach severe criteria with more than $10 \mathrm{mpy}$ for both pipe and elbow with diameter 20 inches or more. The severe corrosion rate of pipe diameters of 20 inches to 40 inches may reach 14 to $17 \mathrm{mpy}$, whereas, the pipe elbow with similar diameter range may reach 12 to 15 mpy. Furthermore, further analysis involves in environmental humidity parameter.

\subsection{Condensation Index}

The condensation index is defined as a condensation level on insulated pipe that influences the corrosion under insulation referred to the most humid environment due to condensation, etc.. Based on the predicted corrosion rate, if pipe diameter of 10 inches at PL-401 KMJ (Kamojang) 17 was operated at a temperature of $183{ }^{\circ} \mathrm{C}$, maximum pressure of 15 bars, and the most humid environment, it would be used as reference to compare the condensation level with the other measuring points. In fact, the pipe diameter of 10 inches was actually operated at pressure of 6.5 bars with measured corrosion rate of 4.05 mpy during last 26 years, and may reach pipe life expectation up to 46.51 years.

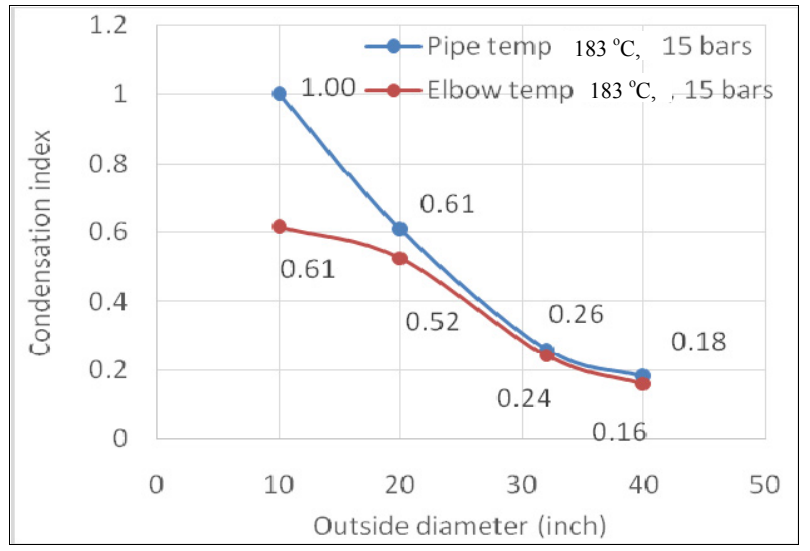

Fig. 3 Condensation index on pipe surface at $183{ }^{\circ} \mathrm{C}, 15$ bars and humid condition.

The enviromental humidity leads to an increase of condensation index that is represented by the ratio of corrosion rate against to the surface area of the insulated pipe. Higher humidity contains more water molecules and dissolved oxygen that promotes the corrosion rates. Fig. 3 shows the condensation level of each sampling points considering further correction on typical heavy duty condition at working temperature $183^{\circ} \mathrm{C}$ and operating pressure of 15 bars.

Although the large pipe diameters of 32 inches and 40 inches indicate severely corrosion rate under insulation, but, these pipes basically did not corrode at the worse situation. It is argued, if the header pipe diameter of 40 inches was exposed in more humid condition, the corrosion rate may sharply increase up to $94.11 \mathrm{mpy}$. In fact, this header pipe diameter of 40 inches was operated at pressure of 10.3 bars with corrosion rate of 13.68 mpy during the last 26 years.

\section{Conclusion}

The CUI dominates metal loss in the case of geothermal field. The header pipe diameters of 32 inches and 40 inches require priority for inspection due to higher corrosion rate compared to smaller pipe diameters. The calculation method was applied under heavy duty condition at pressure of 15 bars and a temperature of $183{ }^{\circ} \mathrm{C}$. It was predicted that corrosion rate will be severely occurred in the pipe diameters of 20 inches, 32 inches and 40 inches. Practically, the 

with Corrosion under Insulation

metal loss at a half thickness requires priority for inspection or possible partial replacement.

\section{Acknowledgement}

The authors would like to thank Indonesia Geothermal Energy for technical support for this work. We also thank A. Karim, and A. Fadli for fruitful discussion and comments.

\section{References}

[1] Tada, T., Suetsugu, H., and Mori, H. 2010. Inspection Technique for Corrosion under Insulation by Using Fiber Optical AE Sensor. R \& D report, Sumitomo Chemical Co. Ltd., Sumitomo Kagaku.

[2] Horrocks, P., Mansfield, D., Parker, K., Thomson, J., Atkinson, T., and Worsley, J. 2010. Managing Ageing Plant, a Summary Guide. A report by Health and Safety
Executive.

[3] Abbas, A. 2012. Corrosion Booklet. ADGAS (Abu Dhabi Gas Liquefaction Company), United Arab Emirates: Abu Dhabi Gas Liquefaction Company.

[4] U.S. Chemical Safety and Hazard Investigation Board. 2012. Chevron Richmond Refinery Fire. Interim investigation report, Chevron Richmond Refinery, Richmond, California.

[5] API 5L. 2004. Specification for Line Pipe, 43rd ed. Washington D.C.: American Petroleum Institute.

[6] Rossum, J. R. 2013. Fundamentals of Metallic Corrosion in Fresh Water. A report by Roscoe Moss Company.

[7] Brondel, D., Edwards, R., Hayman, A., Hill, D., Mehta, S., and Semerad, T. 1994. "Corrosion in the Oil Industry." Oilfield Review 6 (2):4-18.

[8] Heidersbach, R. 2012. Corrosion Survey of Valdez Marine Terminal. Final report of Contract Number 559.12.01.

[9] API 510. 2006. Pressure Vessel Inspection Code, In-Service Inspection, Rating, Repair, and Alteration, 9th ed. Washington D.C.: American Petroleum Institute. 